Article

\title{
Nematicidal Activity of Stevia rebaudiana (Bertoni) Assisted by Phytochemical Analysis
}

\author{
Nikoletta Ntalli ${ }^{1, *}$, Konstantinos M. Kasiotis ${ }^{2}{ }^{(D}$, Eirini Baira ${ }^{2}$, Christos L. Stamatis ${ }^{3}$ and \\ Kyriaki Machera ${ }^{2}$ \\ 1 Laboratory of Biological Control of Pesticides, Department of Pesticides Control and Phytopharmacy, \\ Benaki Phytopathological Institute, 8 St. Delta Street, 14561 Athens, Greece \\ 2 Laboratory of Pesticides' Toxicology, Department of Pesticides Control and Phytopharmacy, Benaki \\ Phytopathological Institute, 8 St. Delta Street, 14561 Athens, Greece; k.kasiotis@bpi.gr (K.M.K.); \\ e.baira@bpi.gr (E.B.); k.machera@bpi.gr (K.M.) \\ 3 Stevia Hellas Coop, 6th klm Lamia-Karpenisi, PS 35131 Lamia, Greece; christos.stamatis@stevianet.gr \\ * Correspondence: n.ntalli@bpi.gr; Tel.: +30-2108-180-343
}

Received: 21 April 2020; Accepted: 10 May 2020; Published: 12 May 2020

check for updates

\begin{abstract}
To date, there has been great demand for ecofriendly nematicides with beneficial properties to the nematode hosting plants. Great efforts are made towards the chemical characterization of botanical extracts exhibiting nematicidal activity against Meloidogyne spp., but only a small percentage of these data are actually used by the chemical industry in order to develop new formulates. On the other hand, the ready to use farmer produced water extracts based on edible plants could be a sustainable and economic solution for low income countries. Herein, we evaluate the nematicidal potential of Stevia rebaudiana grown in Greece against Meloidogyne incognita and Meloidogyne javanica, two most notorious phytoparasitic nematode species causing great losses in tomato cultivation worldwide. In an effort to recycle the plant's remnants, after leaves selection for commercial use, we use both leaves and wooden stems to test for activity. In vitro tests demonstrate significant paralysis activity of both plant parts' water extracts against the second-stage juvenile (J2) of the parasites; while, in vivo bioassays demonstrated the substantial efficacy of leaves' powder $\left(95 \%\right.$ at $\left.1 \mathrm{~g} \mathrm{~kg}^{-1}\right)$ followed by stems. Interestingly, the incorporation of up to $50 \mathrm{~g}$ powder $/ \mathrm{kg}$ of soil is not phytotoxic, which demonstrates the ability to elevate the applied concentration of the nematicidal stevia powder under high inoculum level. Last but not least, the chemical composition analyses using cutting edge analytical methodologies, demonstrated amongst components molecules of already proven nematicidal activity, was exemplified by several flavonoids and essential oil components. Interestingly, and to our knowledge, for the flavonoids, morin and robinin, the anthocyanidin, keracyanin, and a napthalen-2-ol derivative is their first report in Stevia species.
\end{abstract}

Keywords: Meloidogyne incognita; Meloidogyne javanica; phenolics; flavonoids; terpenes; bioactivity

Key Contribution: With this manuscript; we describe; for the first time; the nematicidal activity of Stevia rebaudiana against Meloidogyne incognita and Meloidogyne javanica. We witnessed a paralysis activity against the second-stage juveniles (J2) as well as a nematodes' life cycle inhibition effect in tomato host roots. Chemical composition analysis reveals; amongst constituents; substances of already proven nematicidal activity together with compounds reported herein for the first time.

\section{Introduction}

Stevia rebaudiana (Bertoni) Bertoni (Asteraceae) is mostly known for its contents in vastly sweet ent-kaurane (steviol) diterpene glycosides, natural non-caloric sweeteners, in use in Japan since the 
mid-1970s for sweetening uses [1]. Stevia rebaudiana is internationally known as "Sweet Herb", and as "Caá hê-é" or "Kaá hê-é" and its native country is Paraguay [2-5]. The first reported ethnobotanical information regarding the presence of the sweet-tasting plant S. rebaudiana was made by Bertoni in 1905 and the second followed in 1918 [6,7] and at the beginning the leaves of the plant were used to sweeten maté and tereré drinks, infusion in hot or cold water, respectively [5]. Stevia rebaudiana is cultivated in Taiwan, China, Thailand, Korea, Malaysia, Brazil, Hawaii, Canada, and California [8]. In Greece, a pivotal cultivation region is located in the prefecture of Lamia, Central Greece (see Figure 1), where 57 farmers, members of the Agricultural Cooperative Stevia Hellas, are cultivating organic S. rebaudiana and export throughout Europe.

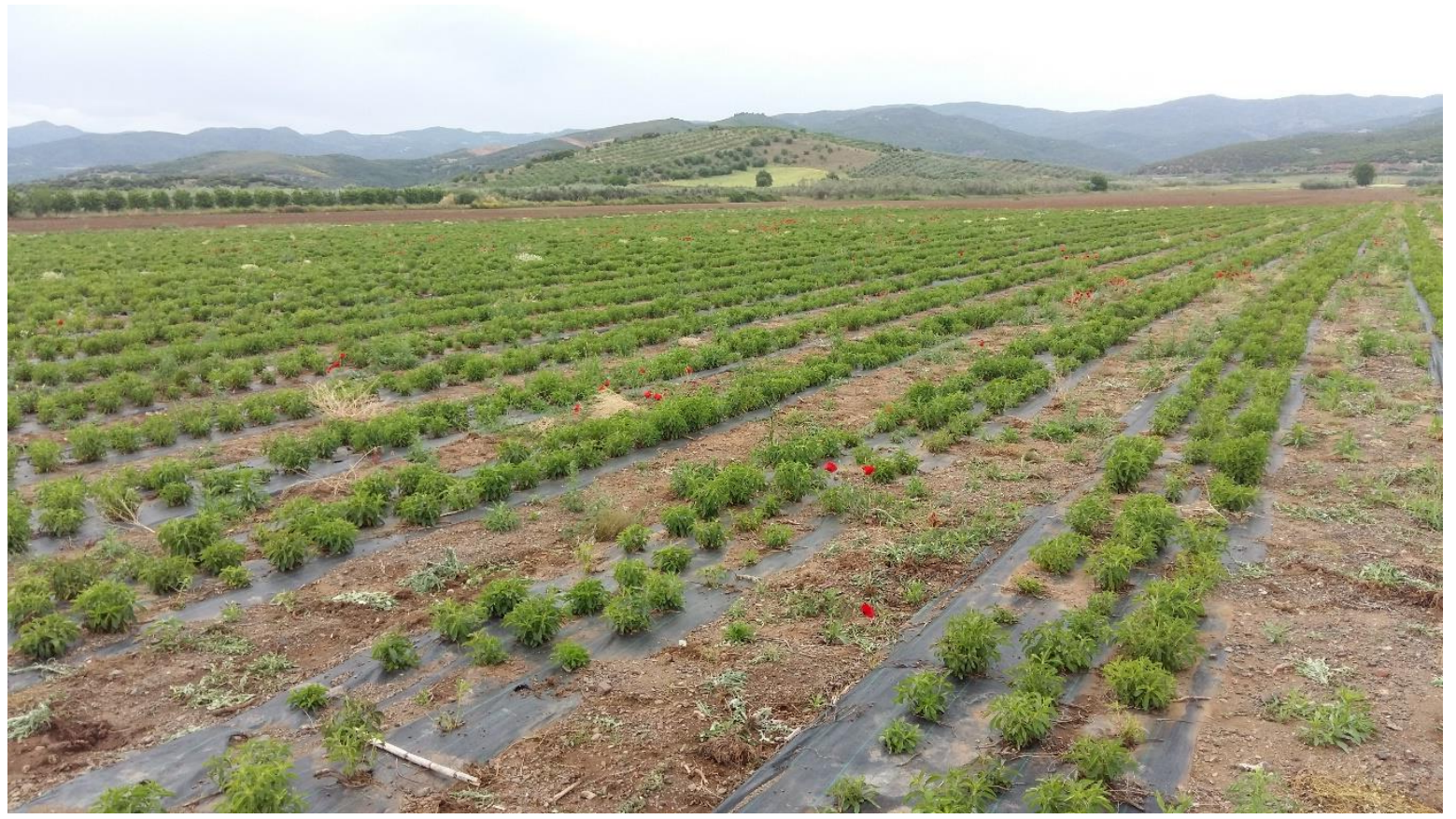

Figure 1. Stevia rebaudiana in cultivation at the Stevia Hellas Coop, 6th klm Lamia-Karpenisi, PS 35131, Lamia, Greece (composite photographs).

To date, S. rebaudiana and its glycosides are becoming more widespread both in the food industry and in the world of science. Specifically, S. rebaudiana preparations have been proven to exhibit various medical properties, like anti-inflammatory, chemo preventive effects, oral health-promoting, anticancer, antihypertensive, anti-hyperglycemic, antimicrobial, antihypertensive, anti-inflammatory, antioxidant, and immune-modulatory [9-11], while its refined extracts have GRAS ("Generally Regarded As Safe") status in the U.S [12]. In the same context, previously major components of S. rebaudiana's essential oil $[13,14]$, such as spathulenol, caryophyllene oxide, manool oxide, trans-nerolinol, and $\alpha$-cadinol are constituents of numerous natural products, with pronounced biological activities. Recently, plant protection properties of $S$. rebaudiana have been published against the phytopathogenic fungi Fusarium oxysporum $[15,16]$ in the frame of developing safe and effective strategies, but alternative to the synthetic, plant protection products. In recent years there is an uprising global need for ecofriendly substitutes to the synthetic pesticides since many chemical groups of formulates have been associated with ecotoxicity concerns and, as a result, have been withdrawn from the market [17,18]. In the frame of discovering bioactive plant secondary metabolites, many are the references on the pesticidal properties of Asteraceae species [19,20] and, in particular, as regards the control of the root knot nematodes, a most harmful agricultural pest damaging crops worldwide [21]. Meloidogyne spp. are obligate endoparasites of plant roots and their reproduction depends on the induction of feeding sites on the host. For some greenhouse cultures, like zucchini, $M$. incognita and $M$. javanica have similar thermal needs to complete their life cycle, while their pathogenic potential (ability to cause disease) might differ in cases [22]. 
The genus Meloidogyne spp. is extremely polyphagous, parasitizing more than 3000 host plants and causing over $\$ 100$ billion in annual crop losses worldwide [23].

S. rebaudiana is rich in plant secondary metabolites of biological activity $[24,25]$ and it could potentially be an alternative nematode control source either through its harvested plant parts or by the culture remnants, which is the non-commercial plant parts, in the frame of the European Waste Framework Directive [26]. In addition, Stevia rebaudiana being an edible plant its un-fractionated and unpurified, crude water extracts could be developed into "basic substances" that is "nematicidal recipes" prepared by the farmer with low risk of harmfulness for soil, water, air, plants or animals [27].

To the best of our acquaintance this is the first report of Stevia rebaudiana as a nematicidal agent against Meloidogyne spp., along with the chemical composition analysis of the nematicidal extracts. In this context, we investigated: (a) the nematicidal potential of $S$. rebaudiana water extracts against two root knot nematodes species, that is M. incognita and M. javanica, in terms of J2 paralysis, (b) the efficacy of the powdered S. rebaudiana culture remnants against $M$. incognita and the secondary effects on tomato plants' growth, and (c) the chemical composition of $S$. rebaudiana extracts in terms of targeted secondary metabolites (e.g glycosides and terpenes) and untargeted metabolomics analysis.

\section{Results}

2.1. Soil Amending with S. rebaudiana Leaves Powder (LP) and Wood Powder (WP) to Treat against M. incognita and Subsequent Biofertilization in Tomato Plants: A Dose-Response

The LP exhibited best activity, since the $\mathrm{EC}_{50}$ value is to be lower that the smallest test concentration used in the tested dose range (Table 1). Specifically, according to nematode female counts per $\mathrm{g}$ of root, the nematicidal activity of LP tested at 1 and $5 \mathrm{~g} \mathrm{~kg}^{-1}$ was $60 \%$ and $95 \%$, respectively (data not shown). The efficacy of NemGuard at the recommended dose $2 \mathrm{mg} \mathrm{kg}^{-1}$ was $95 \%$. On the other hand, a clear dose response relationship was established for WP at the dose range of 1 to $100 \mathrm{~g} \mathrm{~kg}^{-1}$ soil, and the $\mathrm{EC}_{50}$ value was calculated at $3.13 \mathrm{~g} \mathrm{~kg}^{-1}$. Just to show infestation levels under our experimental conditions, we report that the counts of females per $g$ of root tissue in control treatments were $120 \pm 7$. Under no circumstances was phytotoxicity observed at test concentrations, up to $50 \mathrm{~g} \mathrm{~kg}^{-1}$ soil, for both LP and WP (Figure 2). Only stems and roots weights of tomato plants treated with stevia powder at $100 \mathrm{~g} \mathrm{~kg}^{-1}$ soil were found significantly lower when considering control values.

Table 1. Efficacy results expressed as $\mathrm{EC}_{50}\left(\mathrm{~g} \mathrm{kr}^{-1}\right)$ values of $M$. incognita calculated after incorporation of (A) leaves powder (LP) and (B) wood powder (WP) in pots hosting tomato plants artificially inoculated with nematodes. (-) not calculated.

\begin{tabular}{|c|c|c|}
\hline $\begin{array}{c}\mathrm{EC}_{50}\left(\mathrm{~g} \mathrm{~kg}^{-1}\right) \\
\text { (Abbott: }+\mathrm{qg}^{-1} \text { Root) }\end{array}$ & Std. Error & $\mathrm{CI}_{95} \%$ \\
\hline \multicolumn{3}{|c|}{$L P$} \\
\hline$<1$ & - & - \\
\hline \multicolumn{3}{|c|}{$W P$} \\
\hline 3.13 & 0.564 & $1.96-4.29$ \\
\hline
\end{tabular}




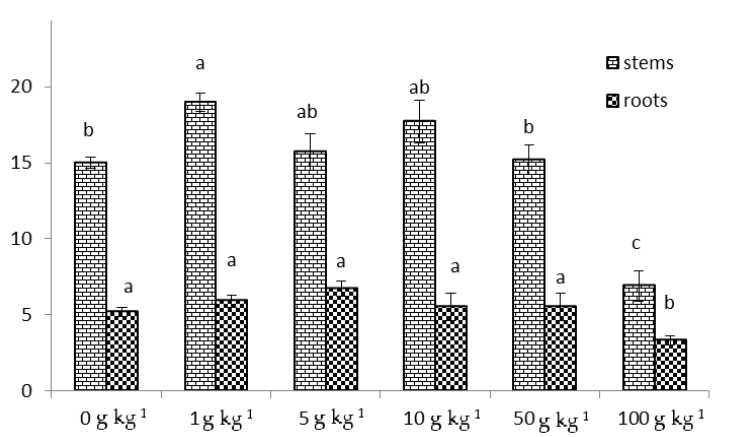

(A)

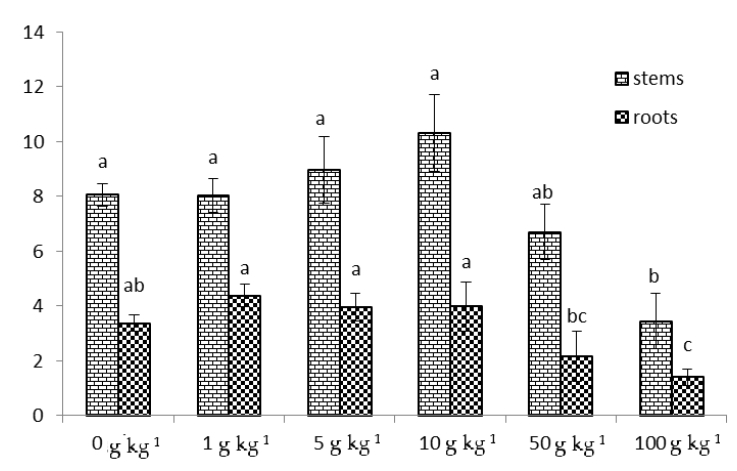

(B)

Figure 2. Tomato stems and root weights (g), as assessed after treatment with (A) leaves powder (LP) and (B) wood powder (WP) for M. incognita control in pot bioassays 40 days post experiment establishment. The data are means of five replicates with standard deviations. The means which are followed by the same letter are not significantly different according to Duncan test $(p \leq 0.05)$. Within each graph letters correspond to statistical differences amongst same pattern bars.

2.2. Paralysis Effect of Leaves Water Extract (LWE) and Wood Water Extract (WWE) on the Plant Parasitic Nematode M. incognita and M. javanica Second Stage Juveniles (J2)

In general, clear dose and time response relationships were established for both LWE and WWE at the dose range of 5.4 to $0.042 \mathrm{mg} \mathrm{mL}^{-1}$ (Table 2). Only in the last assessment date was motility regained to a small extent for $M$. javanica immersed in LWE as well as for M. incognita and M. javanica J2 immersed in WWE. Nonetheless, paralysis exhibited at $48 \mathrm{~h}$ remained constant thereafter, since juveniles moved in plain water never regained activity. Interestingly, the WWE was slower in paralyzing J2, since I $\mathrm{h}$ post experiment establishment no paralysis was evident, but, in the assessments that followed, similar $\mathrm{EC}_{50}$ values were established for both extract and nematode species.

Table 2. Efficacy results expressed as $\mathrm{EC}_{50}(\% \mathrm{w} / \mathrm{v})$ values of $M$. incognita and $M$. javanica after immersion of J2s in test solutions of Leaves Water Extract (LWE) and Wood Water Extract (WWE) for 1, 24, and 48 h. (-) not calculated.

\begin{tabular}{|c|c|c|c|c|}
\hline & Exposure & $\mathrm{EC}_{50}\left(\mathrm{mg} \mathrm{mL}^{-1}\right)$ & Std. Error & $\mathrm{CI}_{95} \%$ \\
\hline & \multicolumn{4}{|c|}{ LWE } \\
\hline & $1 \mathrm{~h}$ & 2.86 & 0.39 & $2.04-3.68$ \\
\hline \multirow[t]{2}{*}{ M. incognita } & $24 \mathrm{~h}$ & 2.30 & 0.29 & $1.70-2.90$ \\
\hline & $48 \mathrm{~h}$ & 1.36 & 0.17 & $1.00-1.73$ \\
\hline \multirow{4}{*}{ M. javanica } & $1 \mathrm{~h}$ & 3.11 & 0.33 & $2.43-3.80$ \\
\hline & $24 \mathrm{~h}$ & 0.41 & 0.04 & $0.32-0.49$ \\
\hline & $48 \mathrm{~h}$ & 0.68 & 0.09 & $0.49-0.88$ \\
\hline & \multicolumn{4}{|c|}{ WWE } \\
\hline \multirow{3}{*}{ M. incognita } & $1 \mathrm{~h}$ & $>5.4$ & - & - \\
\hline & $24 \mathrm{~h}$ & 0.30 & 0.02 & $0.25-0.34$ \\
\hline & $48 \mathrm{~h}$ & 0.95 & 0.07 & $0.79-1.10$ \\
\hline \multirow{3}{*}{ M. javanica } & $1 \mathrm{~h}$ & $>5.4$ & - & - \\
\hline & $24 \mathrm{~h}$ & 0.42 & 0.04 & $0.34-0.51$ \\
\hline & $48 \mathrm{~h}$ & 0.51 & 0.05 & $0.39-0.63$ \\
\hline
\end{tabular}




\subsection{Chemical Composition Analyses of LWE and EO; S. rebaudiana Glycosides and Terpenes Content}

2.3.1. High-Performance Liquid Chromatography-Electrospray Photo Diode Array Mass Spectrometry Analyses of LWE and Constituent Glycosides

The four major steviol glycosides were adequately quantified while using the HPLC-PDA-ESI/MS method, both in leaves (see indicative chromatogram in Figure 3) and stems with marked concentration differences among them. Table 3 presents the analytical results. In addition, a complementary hydrophilic interaction liquid chromatographic mass spectrometric method (HILIC-PDA-ESI/MS) was concomitantly explored (see Figure S1), managing to better discriminate glycosides and resolve them in real extracts from those that share common fragment ions. Nevertheless, preliminary results showed lower sensitivity when compared to the HPLC-PDA-ESI/MS method.

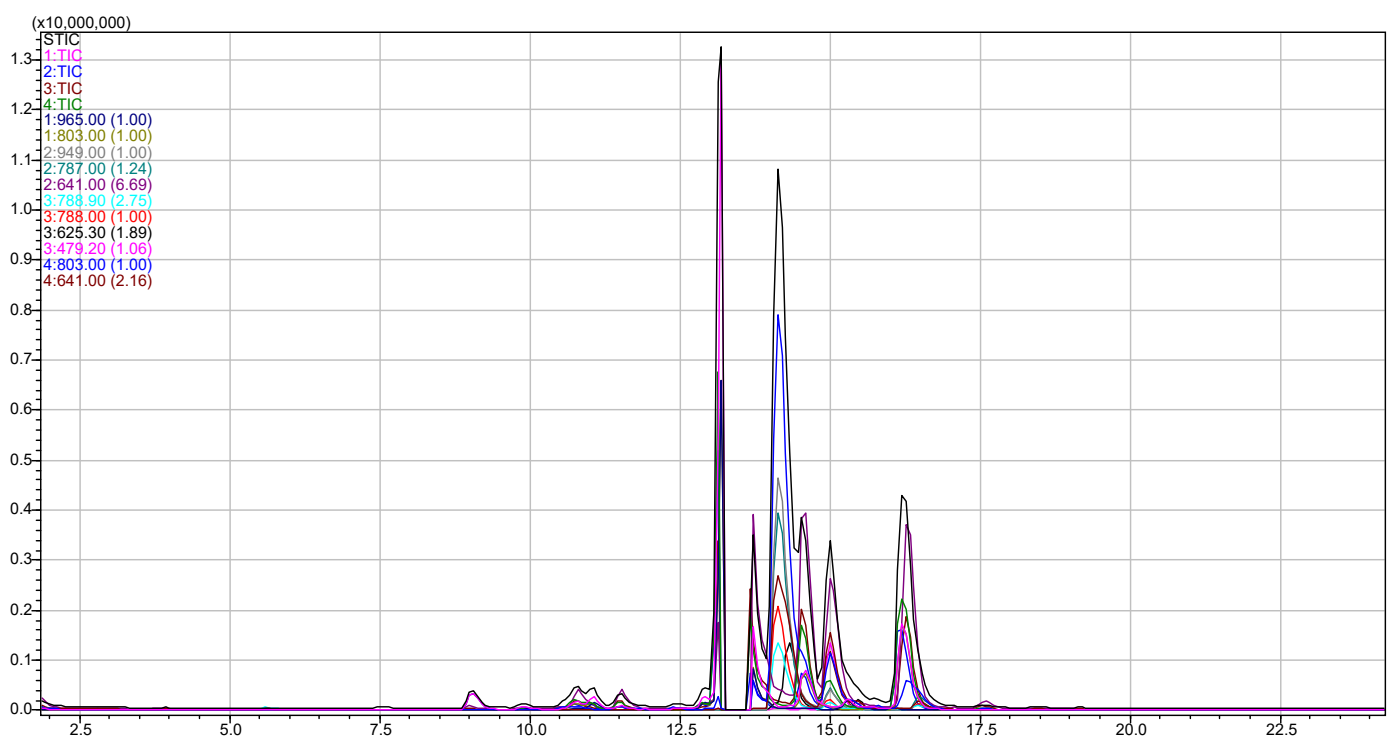

Figure 3. Sum and Individual Total Ion Chromatograms (TICs), and $m / z$ ions of a diluted (100 ppm) LWE.

Table 3. Quantitative results $(n=3)$ for selected-key steviol glycosides determined in Stevia rebaudiana leaves and stems.

\begin{tabular}{ccc}
\hline & S. rebaudiana Leaves & S. rebaudiana Stems \\
\hline Constituent & \multicolumn{1}{c}{ Concentration $\left(\mathbf{m g ~ g}^{-\mathbf{1}}\right) *$} \\
\hline Rebaudioside A & $21.468 \pm 0.181$ & $3.937 \pm 0.045$ \\
Rebaudioside C & $9.679 \pm 0.220$ & $0.643 \pm 0.037$ \\
Dulcoside A & $1.076 \pm 0.047$ & $0.076 \pm 0.003$ \\
Stevioside & $19.729 \pm 0.135$ & $3.625 \pm 0.064$ \\
\hline \multicolumn{3}{c}{${ }^{*} \mathrm{mg} \mathrm{g}^{-1}$ dried leaves or stems. }
\end{tabular}

\subsubsection{Gas Chromatography-Mass Spectrometry Analyses of EO and Constituent Terpenes}

Table 4 depicts the composition of Stevia rebaudiana EO. Tricyclic sesquiterpene alcohol, (-)-spathulenol, caryophyllene oxide, and manool oxide were the major components. 
Table 4. Chemical and relative composition of essential oil of Stevia rebaudiana.

\begin{tabular}{|c|c|c|c|}
\hline Analyte & $\begin{array}{l}\text { Retention } \\
\text { Time (min) }\end{array}$ & $\mathbf{R I} *$ & Relative Amount (\%) \\
\hline$\alpha$-Terpineol & 14.56 & 1189 (1189) & $0.47 \pm 0.08$ \\
\hline$\alpha$-Bourbonene & 19.97 & $1384(1384)$ & $0.15 \pm 0.04$ \\
\hline$\beta$-Maaliene & 20.64 & 1405 (1415) & $0.09 \pm 0.04$ \\
\hline Caryophyllene & 20.92 & 1419 (1417) & $0.32 \pm 0.06$ \\
\hline Aromadendrene & 21.32 & $1440(1439)$ & $0.67 \pm 0.08$ \\
\hline epi- $\beta$-Caryophyllene & 21.86 & $1466(1465)$ & $1.02 \pm 0.11$ \\
\hline$\beta$-Guaiene & 22.00 & $1490(1490)$ & $0.77 \pm 0.09$ \\
\hline$\beta$-Ionone & 22.62 & $1491(1490)$ & $3.11 \pm 0.21$ \\
\hline Eremophilene & 22.97 & $1499(1502)$ & $1.02 \pm 0.15$ \\
\hline$\gamma$-Cadinene & 23.42 & $1513(1511)$ & $1.24 \pm 0.09$ \\
\hline$(-)-\beta$-Cadinene & 23.63 & $1518(1518)$ & $1.33 \pm 0.23$ \\
\hline Cadala-1(10),3,8-triene & 24.14 & $1555(1562)$ & $0.36 \pm 0.05$ \\
\hline Nerolidol & 24.60 & $1564(1565)$ & $2.83 \pm 0.33$ \\
\hline (-)-Spathulenol & 25.08 & $1577(1578)$ & $22.81 \pm 1.49$ \\
\hline Caryophyllene oxide & 25.19 & $1581(1582)$ & $20.18 \pm 1.15$ \\
\hline Isoaromadendrene epoxide & 25.81 & $1589(1594)$ & $4.24 \pm 0.41$ \\
\hline t-Cadinol & 26.55 & $1640(1639)$ & $5.88 \pm 0.52$ \\
\hline$\alpha$-Cadinol & 26.87 & $1653(1650)$ & $3.82 \pm 0.27$ \\
\hline $\begin{array}{l}\text { 6-Isopropenyl-4,8a-dimethyl-1,2,3,5,6,7,8,8a- } \\
\text { octahydro-napthalen-2-ol }\end{array}$ & 27.30 & $1690(1690)$ & $3.10 \pm 0.28$ \\
\hline Ent-Germacra-4(15),5,10,(14)-trien- $1 \beta$-ol & 27.66 & $1695(1694.5)$ & $0.73 \pm 0.10$ \\
\hline Unidentified & 32.97 & - & $1.92 \pm 0.15$ \\
\hline Unidentified & 33.24 & - & $3.03 \pm 0.30$ \\
\hline Unidentified & 33.60 & - & $1.63 \pm 0.29$ \\
\hline Manool oxide & 34.3 & 1992 (1989) & $17.19 \pm 1.02$ \\
\hline Epimanoyl oxide & 34.76 & $2011(2010)$ & $1.74 \pm 0.27$ \\
\hline Oxomanoyl oxide & 38.66 & $2207(2208)$ & $0.35 \pm 0.10$ \\
\hline
\end{tabular}

${ }^{*} \mathrm{RI}$, retention index on HP5-MS UI column (relative to $n$-alkanes), identification based on mass spectra comparison with the reference databases, and comparison with literature RIs (depicted in parentheses).

2.4. Other Compounds Constituing Nematicidal Leaves Water Extract (LWE) and Wood Water Extract (WWE) Identified by Means of Ultra High Performance Liquid Chromatography Coupled to Orbitrap High Resolution Mass Spectrometry (UHPLC-HRMS)

Non-Targeted analysis of a leave and wood (stem) water extract was performed using UHPLC-HRMS. For the data processing procedure, the Compound Discoverer 2.1 software (Thermo Fisher Scientific, San Jose, CA, USA) was employed for retention time alignment, peak alignment, feature extraction, and detection of unknown compounds. For the annotation of the compound, the online $\mathrm{MS}^{2}$-library $\mathrm{mzCloud}$ was used. For the evaluation of the results from mzCloud library, the internal standards chlorogenic acid, rutin, quercitrin, and apigenin were included into the analysis. Table 5 presents the results after the analysis. Figure 4 presents the chromatogram and spectrum of quercitrin on LWE of $S$. rebaudiana compared to the internal standard. 
Table 5. Identification and potential annotation of compounds from leaves water extract (LWE) and wood water extract (WWE) by means of Ultra High Performance Liquid Chromatography coupled to Orbitrap High Resolution Mass Spectrometry (UHPLC-HRMS) analysis.

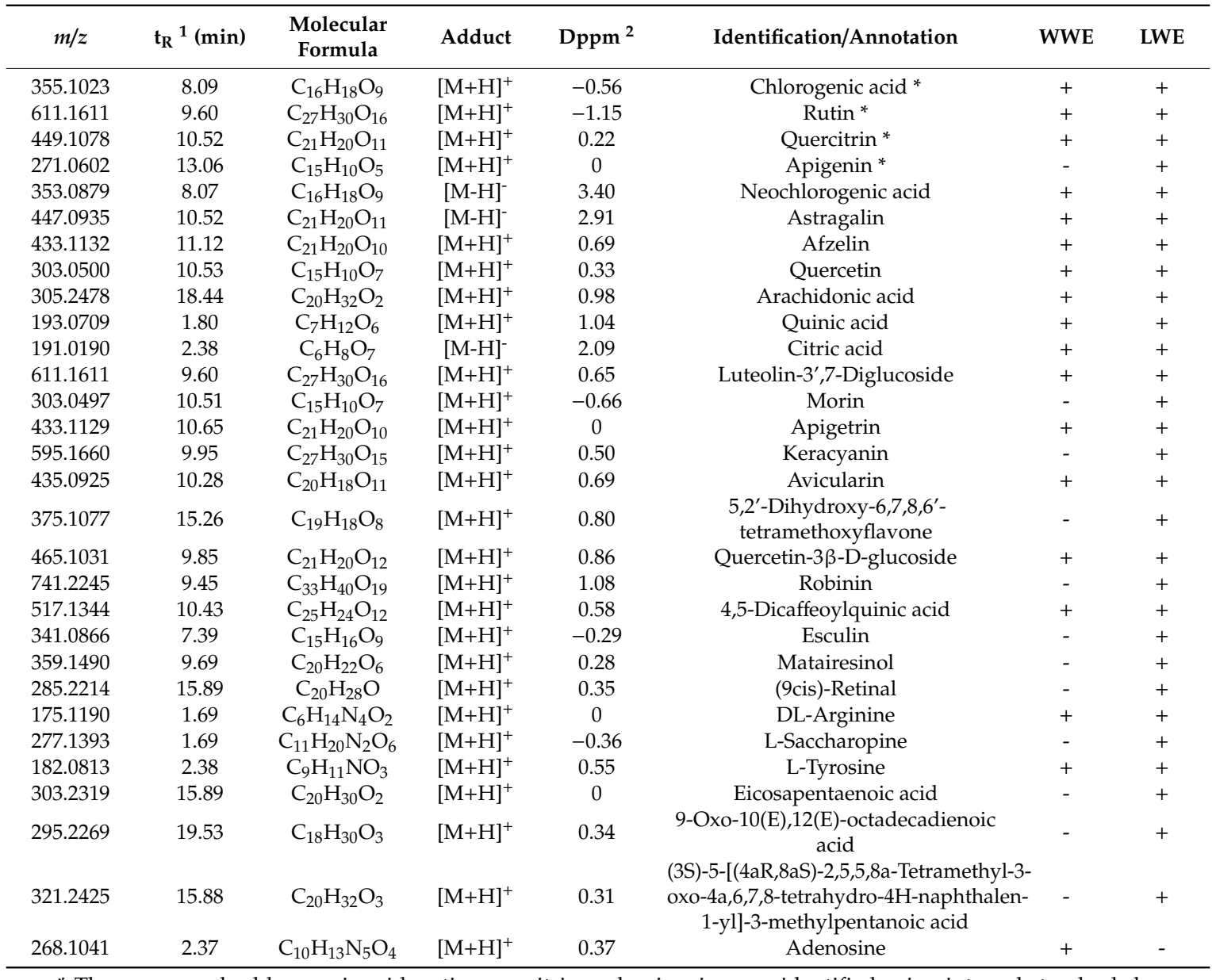

* The compounds chlorogenic acid, rutin, quercitrin and apigenin were identified using internal standards by comparing the accurate mass, the retention time and the MS/MS fragmentation pattern. The rest of compounds were annotated based on the mzCloud library. ${ }^{1}$. $t_{R}$, retention time, ${ }^{2}$. Dppm, mass error in ppm. 

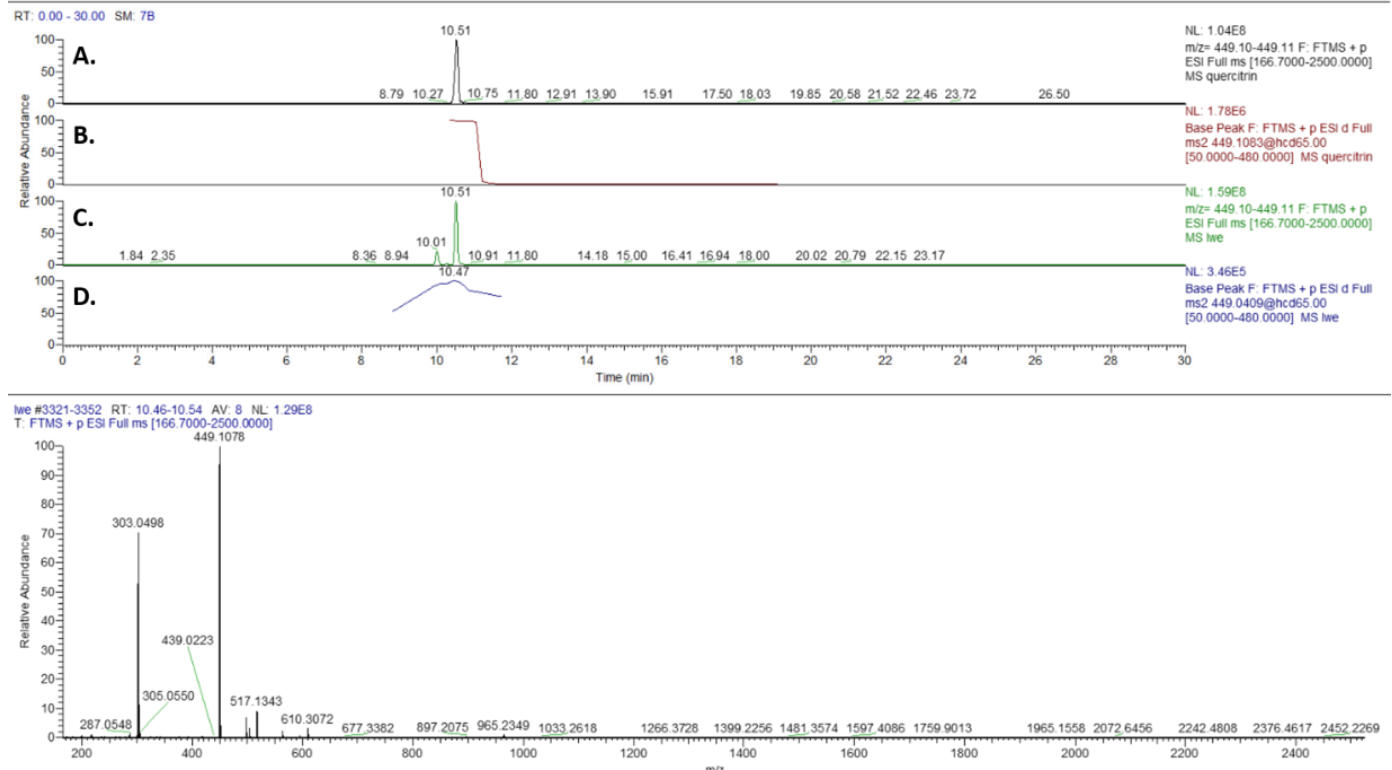

Figure 4. The UHPLC-HRMS chromatograms of the internal standard quercitrin (A) and the LWE of S. rebaudiana $(\mathbf{C})$ accompanied by the respective spectrums $(\mathbf{B}, \mathbf{D})$.

\section{Discussion}

The purification of phytochemicals and their structural elucidation of the sweet-tasting glycosides of steviol from S. rebaudiana leaves began approximately 90 years ago when its most abundant entkaurane glycoside, named stevioside, was extracted and crystallized [28]. Other major components whose elucidation followed were rebaudioside [29], rebaudiosides B-E, steviolbioside, and dulcoside A [30-32]. To date the stated specifications of the Codex Committee on Food Additives, by the Joint FAO/WHO Expert Committee on Food Additives (JECFA) of Europe, considering food products produced from $S$. rebaudiana leaves are represented by a minimum of $95 \%$ steviol glycosides. The compounds presented are stevioside, rebaudiosides A-F, rubusoside, steviolbioside, and dulcoside A [12] (Figure 5). Other than the steviol glycosides, we have identified various chemical groups of compounds, like phenols, flavonoids, terpenes, coumarin based analogues, amino and fatty acids, some of them of already proved nematicidal activity. Specifically, we previously reported the paralysis potential of terpinen-4-ol and $\beta$-caryophyllene and against $M$. incognita to exhibit an $\mathrm{EC}_{50 / 96 \mathrm{~h}}$ value of 168 and $307 \mu \mathrm{g} \mathrm{mL}^{-1}$, respectively [33]. Interestingly, one of the major components, caryophyllene oxide, was not toxic to $\mathrm{J} 2 \mathrm{up}$ to the concentration of $2000 \mu \mathrm{g} \mathrm{mL} \mathrm{m}^{-1}$ [34], while no reports exist on the nematicidal activity of manool oxide against Meloidogyne spp., Interestingly, essential oils containing (-)-spathulenol have exhibited nematicidal activity against Meloidogyne spp. [35,36]. To our knowledge, herein, the first report of 6-isopropenyl-4,8a-dimethyl-1,2,3,5,6,7,8,8a-octahydro-napthalen-2-ol in S. rebaudiana is provided. This napthalen-2-ol derivative has been reported as a constituent of the bioactive extract of Scapania verrucose [37], and of the bioactive root essential oil from the species Jatropha ribifolia [38]. According to the UHPLC-HRMS analysis of the extracts, chlorogenic acid and the flavonoids rutin, quercitrin (see its UHPLC-HRMS identification in Figure 4) and apigenin were identified while using internal standards. Additionally, several other compounds were annotated using the online library mzCloud. The majority of these constituents are largely in agreement with the ones reported in the literature on the phenolic and antioxidant compounds composition of $S$. rebaudiana $[24,25,39]$. To our knowledge, for some of these, it is their first putative identification in S. rebaudiana. More specifically, the flavonol compound, morin, and the kaempferol derivative, robinin (or kaempferol-3 O-robinoside-7-O-rhamnoside) first appear in S. rebaudiana. The flavonoids superfamily is known for their contribution to the chemotactic repulsion of nematodes away from the root, and their overall role in the interaction of plant-nematodes [40]. Interestingly, for the anthocyanin chloride derivative, keracyanin, it is also its first report as a constituent 
in S. rebaudiana species. Hence, this finding opens new frontiers in the chemical classes underscored in $S$. rebaudiana, unveiling new potential biosynthetic pathways in this important crop. With regard to other flavonoid counterparts, quercitrin was already isolated as one of the bioactive molecules of the aerial plant parts of Caragana leucophloea Pojark. (Leguminosae) [41]. Rutin was found among constituent components of the nematicidal Croton ehrenbergii growing unharmed amidst predators and exhibiting an innate defense mechanism against predators [42]. Quercitrin, afzelin, and quercetin were some of the phenolic components of the leaves of Schinus terebinthifolius significantly active against M. incognita [43]. Chlorogenic acid was a major component of the nematicidal water extract of Mentha piperita, Mentha pulegium, and Mentha spicata exhibiting significant activity against $M$. incognita [44]. Arachidonic acid is considered to be a biogenic elicitor, at concentrations of $0.1-10 \mu \mathrm{M}$, shown to ensure systemic, long-term protection against M. incognita [45]. Aqueous extracts of Pistacia lentiscus (L.) rich in phenolics, including quinic acid, were found active against $M$. javanica [46]. The flavonoid apigenin as isolated from the aerial parts of the species Caragana leucophloea Pojark. (Leguminosae) was proven to be of considerable nematicidal activity against Caenorhabditis elegans [41]. Last but not least, an amino acid containing plant leaf extract have exhibited nematicidal properties against Caenorhabditis elegans [47]. Hence, amino acids identified in this work can interplay in the demonstrated nematicidal activity.

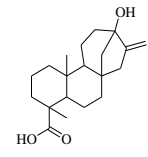

Steviol

$\left(\mathrm{C}_{20} \mathrm{H}_{30} \mathrm{O}_{3} ; \mathrm{MW}: 318.4\right)$

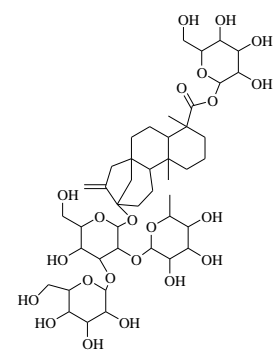

Rebaudioside C ( $\left.\mathrm{C}_{44} \mathrm{H}_{70} \mathrm{O}_{22} ; \mathrm{MW}: 951.0\right)$

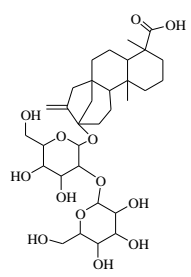

Steviobioside ( $\mathrm{C}_{32} \mathrm{H}_{50} \mathrm{O}_{13} ; \mathrm{MW}: 642.7$ )

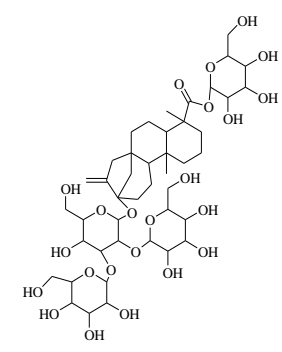

Rebaudioside A $\left(\mathrm{C}_{44} \mathrm{H}_{70} \mathrm{O}_{23} ; \mathrm{MW}: 967.1\right)$

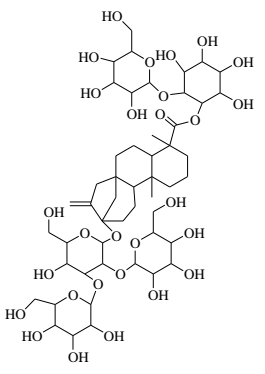

Rebaudioside D $\left(\mathrm{C}_{50} \mathrm{H}_{80} \mathrm{O}_{28}\right.$; MW:1129.2)

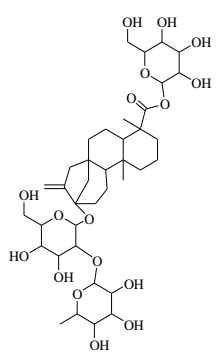

Dulcoside A ( $\mathrm{C}_{38} \mathrm{H}_{60} \mathrm{O}_{17} ; \mathrm{MW}$ :788.9)

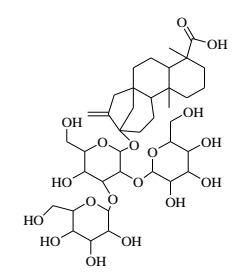

Rebaudioside B ( $\left.\mathrm{C}_{38} \mathrm{H}_{60} \mathrm{O}_{18} ; \mathrm{MW}: 804.9\right)$

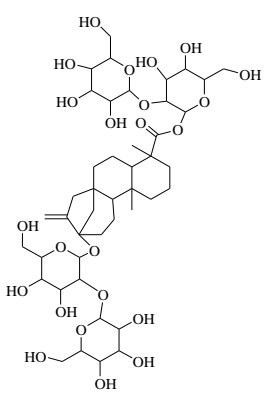

Rebaudioside E $\left(\mathrm{C}_{44} \mathrm{H}_{70} \mathrm{O}_{23} ; \mathrm{MW}: 967.1\right)$

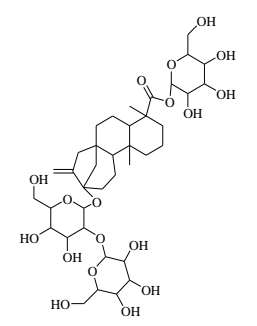

Stevioside ( $\left.\mathrm{C}_{33} \mathrm{H}_{60} \mathrm{O}_{18} ; \mathrm{MW}: 804.9\right)$

Figure 5. Steviol glycosides of the species S. rebaudiana. 


\section{Conclusions}

According to our findings, S. rebaudiana, apart from being a natural non-caloric sweetener with significant medical properties for consumers, additionally exhibits noteworthy plant protection properties against the most notorious Meloidogyne incognita with no phytotoxicity issues on tomato host plants. The development of ecofriendly bionematicides to substitute their synthetic ancestors is now mandatory and it becomes more feasible for active plant secondary metabolites freely available in cultivated plants for food. Because both the commercialized S. rebaudiana leaves and the culture stem remnants were of nematicidal activity, the latter being freely available could be economically recycled into nematode control tools. We are now in the process of testing more by-products of the S. rebaudiana sweetener products chain, against $M$. incognita, delineating among constituents for activity. Further steps envisage the inclusion of all steviol glycosides in the respective analytical methods, alongside the in-depth exploration of bioactive compounds in S. rebaudiana.

\section{Materials and Methods}

\subsection{Plant Material, Nematodes Populations and Reagents}

Stevia rebaudiana was cultivated as an organic culture in Lamia region of Greece. The aerial parts were collected when plants had reached 10-15\% of full flowering at early July 2019 and the leaves were separated from stems (wood) and then dried in the dark at room temperature. Subsequently, they were sealed in paper bags and kept at room temperature, in the dark, until use for no longer that one month. The variety cultivated in 2019 was named SugHigh A3 and it was a kind offer of Ever Stevia, Toronto, Canada.

Nematode populations of $M$. incognita and $M$. javanica were initiated from two single eggmasses of Greek origin. They were reared on tomato plants cv. Belladonna, a variety that was susceptible to nematodes' infestation. Freshly hatched $(24 \mathrm{~h})$ nematodes at the stage of second-stage juveniles (J2) were obtained according to the method of Hussey and Barker (1973) [48] from 60 day-old (d) infested roots, and were thereafter used for the experiments.

Stevioside (98.1\%), Rebaudioside A (99.5\%), Rebaudioside C (99.3\%), Dulcoside A (98\%), and acid fuchsin were obtained from Sigma-Aldrich (Buchs, Switzerland). Water, acetonitrile, methanol and formic acid were purchased from Fisher Scientific, UK and they were of LC-MS grade. Acetone used in GC-MS analysis was of pesticide residue grade and obtained from Fisher Scientific. PTFE filters $(0.45 \mu \mathrm{m})$ were obtained from Macherey-Nagel, Düren Germany.

\subsection{Soil Amending with S. rebaudiana Leaves Powder (LP) and Wood Powder (WP) to Treat against M. incognita and Subsequent Biofertilization in Tomato Plants: A Dose-Response}

The sandy loam soil (clay: 18\%, silt: $22 \%$, sand: $60 \%$ ), with $\mathrm{pH} 6.5,3.3 \%$ organic carbon, and $1.9 \mathrm{mg} \mathrm{g}^{-1}$ total $\mathrm{N}$ was collected from a noncultivated field of the Benaki Phytopathological Institute. Initially it was sieved through 3-mm and partially air dried overnight. The maximum water holding capacity and soil moisture were calculated according to Pantelelis et al., 2006 [49] and then a mixture with sand at a ratio of 2:1 was prepared to form the hereafter referred to soil. Six plastic bags represented the experimental treatments, $1 \mathrm{~kg}$ of soil each receiving a nematode inoculation $2500 \mathrm{~J} 2$ $\mathrm{kg}^{-1}$. After appropriate mixing and overnight incubation at room temperature according to Ntalli et al., 2020 [50] the plastic bags were spiked with appropriate amounts of LP and WP to reach the test concentrations of $1,5,10,50$, and $100 \mathrm{~g} \mathrm{~kg}^{-1}$ soil. NEMguard SC (garlic extract by Intrachem) was used as a commercial control at the recommended dose $\left(4 \mathrm{~L} \mathrm{ha}^{-1}\right.$ that is $2 \mu \mathrm{L}$ of formulated product per $\mathrm{kg}$ soil or $2 \mathrm{mg}$ of a.i per $\mathrm{kg}$ of soil) [51]. A water control was also included in the experiment. Seven-week old tomato plants, cv. Belladonna were transplanted into the treated soil, separated in five different pots containing $200 \mathrm{~g}$ of soil each, and the bioassay was kept at $27^{\circ} \mathrm{C}, 60 \%$ relative humidity at $16 \mathrm{~h}$ photoperiod for 40 days. Every pot received $20 \mathrm{~mL}$ of water every three days and forty days; afterwards, plants were uprooted and gently washed. Shoots were separated from roots and the latter 
were stained with acid fuchsin, according to Byrd et al. (1983) [52], and the following parameters were assessed: (1) M. incognita females per g of root at 10× magnification control, (2) fresh stems weight, and (3) fresh root weight. The experiment was performed twice, and the treatments were arranged in a completely randomized design with five replicates.

\subsection{Essential Oil (EO) and Water Extracts (LWE E WWE) Production}

The dried S. rebaudiana plant material was water distilled in a Clevenger apparatus (Winzer, Wertheim, Germany) for $3 \mathrm{~h}$ at a ratio of $1 / 10(w / v)$ plant parts/water volume. The attained EO was dried over anhydrous $\mathrm{Na}_{2} \mathrm{SO}_{4}$ and was stored in dark glass vial with Teflon-sealed caps at $-2.0 \pm 0.5^{\circ} \mathrm{C}$ until use. Before the chemical analysis, the $\mathrm{EO}$ was allowed to gradually reach ambient temperature. The yield of EO was determined as an average of three replicates and it was $0.004 \%(w / w)$ (data not shown).

The water extract was prepared by mixing the dried stevia leaves or wood with distilled water at a ratio of 1/10 (w/v) and then sonicated for $15 \mathrm{~min}$. (Branson 1210, Marshall Scientific, Hampton, NH, USA). In extends, a filtration was performed through a Whatman no. 40 filter paper (Whatman International Ltd., Maidstone, England). All of the extracts were used fresh for bioassays. The S. rebaudiana yield in dry LE and WE extract were 10.8 and 10.5\% $(w / w)$, respectively, as calculated after exhaustive evaporation of the solvent (data not shown). It must be noted that this extraction method is not the one optimized for total glycosides acquirement.

\subsection{Paralysis Effect of Leaves Water Extract (LWE) and Wood Water Extract (WWE) on the Plant Parasitic} Nematode M. incognita and M. javanica Second Stage Juveniles (J2)

The nematicidal potential of LWE and WWE, in terms of J2 paralysis, was studied, and the $\mathrm{EC}_{50}$ values were established. The water extract of leaves (LWE) and of wood (WWE) were both prepared by mixing the dried $S$. rebaudiana parts with distilled water at a ratio of 1/10 (w/v), sonicated for $15 \mathrm{~min}$. and filtered, as stated in the previous paragraph. For each extract, a separate dose-response bioassay was performed at the range level of 5.4 to $0.042 \mathrm{mg} \mathrm{mL}^{-1}$. Crude extracts were used as stock solutions and working solutions were prepared with subsequent dilutions in distilled water. All of the test solutions were expressed per dry extract after having calculated the extract dry yield by exhaustive evaporation of the solvent (water). Distilled water served as control. Around fifteen J2 were employed per treatment well in Cellstar 96-well plates (Greiner bio-one, Frickenhausen, Germany). The plates were shielded and kept in the dark at $28{ }^{\circ} \mathrm{C}$. Border wells were used to check the vapor drift. Juveniles were observed with the aid of an inverted microscope (Euromex, Arnhem, The Netherlands) at 40x after 1, 24, and $48 \mathrm{~h}$ and were separated into: motile or paralyzed. After the last assessment (48 h), the nematodes were transferred into plain water and they were evaluated again after $24 \mathrm{~h}$ for motility regain. Paralysis treatments were replicated six times, and every experiment was performed twice.

\subsection{High-Performance Liquid Chromatography - Photo Diode Array Electrospray Mass Spectrometry Analyses} of LWE

HPLC-DAD-ESI/MS conducted the chemical analysis of steviol glycosides. A Shimadzu (Kyoto, Japan) LCMS-2010 EV Liquid Chromatograph Mass Spectrometer instrument was used with the LCMS solution version 3.0 software consisting of an SIL-20A prominence autosampler and an SPD-M20A diode array detector. These compartments were in conjunction with a mass selective detector that was equipped with an atmospheric pressure ionization. The HPLC separation (three replicates were analyzed) was accomplished on a Zorbax Eclipse Plus, $3.5 \mu \mathrm{m}, 150 \times 2.6 \mathrm{~mm}$ i.d. chromatographic column. The mobile phase solvents composed of: (A), $0.1 \%$ formic acid in water, (B), $0.1 \%$ formic acid in acetonitrile, and $(\mathrm{C})$, Methanol. The flow rate was set at $0.3 \mathrm{~mL} \mathrm{~min} .^{-1}$ and the mobile phase was identical with the one mentioned in the literature [53], with modification in the gradient, since not all steviol glycosides were included. The overall runtime was established at 25 min. Electron Spray Ionization (ESI) mode, using four distinct events for each analyte (see Table S1 and Figures S2 and S3), 
was applied in the selected ion monitoring mode (SIM). Photodiode array monitored wavelengths in the range of $190-800 \mathrm{~nm}$.

\subsection{Gas Chromatography-Mass Spectrometry Analyses of EO}

The GC-MS analysis was performed on a Chromtech Evolution 3 MS/MS triple quadrupole mass spectrometer that was built on an Agilent 5975 B inert XL EI/CI MSD system that was operated in full scan data acquisition mode, covering a mass range from $m / z 50$ to 500 . The samples were injected with a Gerstel MPS-2 autosampler using a 10- $\mu \mathrm{L}$ syringe. Separations were performed on the chromatographic column Agilent J\&W HP-5ms Ultra-Inert (UI), length 30m, Inner Diameter (ID) $0.25 \mathrm{~mm}$, film thickness $0.25 \mu \mathrm{m}$ (Agilent Technologies, Santa Clara, CA, USA). Helium (99.9999\% purity) was used as the carrier gas at a flow rate of $1.2 \mathrm{~mL} \mathrm{~min}^{-1}$. The column oven temperature program started from $45^{\circ} \mathrm{C}$, staying for $1 \mathrm{~min}$, increased to $250{ }^{\circ} \mathrm{C}$ at a rate of $5{ }^{\circ} \mathrm{C} \mathrm{min}{ }^{-1}$, where it remained for $5 \mathrm{~min}$. The transfer line, manifold, and source of ionization temperatures were 300, 40 and $230{ }^{\circ} \mathrm{C}$, respectively. The electron multiplier voltage was set at $2000 \mathrm{~V}$. The total GC analysis was $47 \mathrm{~min}$. (see respective chromatogram in Figure S3). The identified peaks in GC-MS (triplicate analysis) were confirmed by comparing the acquired mass spectra with those in the commercial library of NIST 08.

\section{Analytical Method Validation-Quantitation of Components}

The analytical method was validated consulting primarily the International Conference on Harmonization (ICH) [54], a SANTE guideline (SANTE/11813/2017) [55], and a pertinent publication [56] . The validation study concerned recovery, linearity, intra-day, and inter-day precision. Calibration curves, which were established using the dilute standard solution of the four analytes, varied from 40 to $2000 \mathrm{ng} \mathrm{mL}^{-1}$. Blank experiments were also performed, without the matrix extract. Standard addition was used for the recovery study (two concentration levels).

More specifically, the precision of the chromatographic method was expressed as the relative standard deviation values (RSD \%) of the repeatability (intra-day) and intermediate precision (inter-day) analyses $(n=3)$ over one, two, and three days. Repeatability and intermediate precision were considered acceptable when RSD\% were $<20 \%$. Limit of Quantitation(s) (LoQs) were defined as the lowest validated spiked level (at $40 \mathrm{ng} \mathrm{g}^{-1}$, equivalent to $40 \mathrm{ng} \mathrm{mL}^{-1}$ ) that met the method performance acceptability criteria, regarding mean recoveries in the range of 70-120\%, with RSDr 20\% (for analytical method validation characteristics see Table S2). With regard to the Limit of Detection (LoD) values, they were defined as three times the baseline noise of the signals produced after injecting low concentration standards solutions of the four steviol glycosides mix (blank matrix is not available for stevia) (see LoD values in Table S2). Since the filtering of extracts prior to chemical analysis can affect the recovery of bioactive compounds from natural products, the filters used in this study were assessed for this purpose. The results showed a negligible effect on the recovery of the glycosides (analysis conducted before and after filtering).

To calculate matrix effects, the slopes of the calibration lines that were obtained for S. rebaudiana extracts after standard addition $\left(b_{\text {matrix }}\right)$ and the solvent $\left(b_{\text {solvent }}\right)$ were divided in order to determine the matrix factor and the \% matrix effect (ME) was calculated by Equation (1).

$$
\% \mathrm{ME}=\left(1-\mathrm{b}_{\text {matrix }} / \mathrm{b}_{\text {solvent }}\right) \times 100
$$

5.7. Ultra High Performance Liquid Chromatpgraphy-Coupled to Orbitrap High Resolution Mass Spectrometry Analysis of Leaves Water Extract (LWE) and Wood Water Extract (WWE)

Metabolite profiling of the extracts (triplicate analysis) was performed on a Dionex Ultimate 3000 UHPLC system (Thermo Scientific ${ }^{\mathrm{TM}}$ Dionex $^{\mathrm{TM}}$, Sunnyvale, CA, USA) that was equipped with Q-Exactive Orbitrap mass spectrometer (Thermo Fisher Scientific, San Jose, CA, USA) on positive (ESI+) and negative (ESI-) ion mode. Chromatographic separation was achieved on a Hypersil Gold UPLC 
C18 $(2.1 \times 150 \mathrm{~mm}, 1.9 \mu \mathrm{m})$ reversed phased column (Thermo Fisher Scientific, San Jose, CA, USA). The mobile phases consisted of (A) ultrapure water with $0.1 \%$ formic acid and (B) acetonitrile. The elution gradient was set, as follows: 0 to $21 \mathrm{~min}$ : 95\% A: 5\% B, 21 to $24 \mathrm{~min}: 5 \% \mathrm{~A}: 95 \% \mathrm{~B}, 24$ to $30 \mathrm{~min}$ : 95\% A: $5 \% \mathrm{~B}$. The eluent flow rate was maintained at $0.22 \mathrm{~mL} \mathrm{~min}^{-1}$ and the $\mathrm{m} / z$ ranges were set to $150-2500 \mathrm{Da}$ on profile mode. HRMS operation parameters for both negative and positive modes were set as follows: capillary temperature, $350{ }^{\circ} \mathrm{C}$; spray voltage, $2.7 \mathrm{kV}$; S-lense Rf level, $50 \mathrm{~V}$; sheath gas flow, 40 arb. units; aux gas flow, 5 arb. units; aux. gas heater temperature, $50^{\circ} \mathrm{C}$. Each sample was analyzed in full scan mode at a resolving power of 70,000, whereas, for the data dependent acquisition mode, the resolution was 35,000 allowing for MS/MS fragmentation of the three most intense ions. Stepped normalized collision energy was set at 35,60, and 100. The column temperature was kept throughout the analysis at $40{ }^{\circ} \mathrm{C}$, while the sample tray temperature was set at $4{ }^{\circ} \mathrm{C}$. A $5 \mu \mathrm{L}$ aliquot of each sample was injected. Data analysis was achieved using Compound Discoverer 2.1 software (Thermo Fisher Scientific, San Jose, CA, USA) for alignment, peak peaking, and grouping. For metabolite annotation, the online $\mathrm{MS}^{2}$-library $\mathrm{mzCloud}$ was used applying $\mathrm{m} / \mathrm{z}$ tolerance of $5 \mathrm{ppm}$ and taking into consideration the isotopic and MS/MS fragmentation pattern.

\subsection{Statistics}

Natural death/paralysis was eradicated according to the Schneider Orelli formula [57], which is corrected $\%=[($ mortality $\%$ in treatment - mortality $\%$ in control $) /(100-$ mortality $\%$ in control $)\}] \times 100$, and experiments analyzed (ANOVA) were combined over time. The means were averaged over bioassays since ANOVA showed no significant treatment by time interaction. Corrected percentages of paralyzed J2 were subjected to nonlinear regression analysis using the log-logistic equation proposed by Seefeldt et al. [58]: Y $=C \mathrm{p}(\mathrm{D}-\mathrm{C}) /\{1 \mathrm{p} \exp [\mathrm{b}(\log (\mathrm{x})-\log (\mathrm{EC} 50))]\}$, where $\mathrm{C}=$ the lower limit, $\mathrm{D}=$ the upper limit, $\mathrm{b}=$ the slope at the $\mathrm{EC}_{50}$, and $\mathrm{EC}_{50}=$ the test concentration required for $50 \%$ death/paralysis after removal of the control (natural death/paralysis). In the regression equation, the test concentration was the independent variable $(\mathrm{x})$ and the paralyzed $\mathrm{J} 2$ (percentage increase over water control) was the dependent variable (y). The mean value of the six replicates per test concentration and immersion period was used to calculate the $\mathrm{EC}_{50}$ value. The $95 \%$ confidence intervals (95\% CI) were determined for toxicity comparison.

The means were averaged over bioassays when considering pot bioassays and since ANOVAs showed no significant treatment between runs of experiment. The data from the pot bioassays were expressed as a percentage decrease in the number of females per $g$ of root corrected according to the control (water), using the Abbott's formula: corrected $\%=100 \times\{1-$ [females number in treated plot/females number in control plot]\}. It was fitted in the log-logistic model, as for paralysis data, in order to estimate the concentration that caused a 50\% decrease in females per $\mathrm{g}$ of root (EC 50 value). The $95 \%$ confidence intervals (95\% CI) were determined for toxicity comparison.

Supplementary Materials: The following are available online at http://www.mdpi.com/2072-6651/12/5/319/s1, Table S1. Characterization of steviol glycosides by HPLC-DAD-ESI/MS, Table S2. HPLC-PDA-ESI/MS Analytical Method Validation Characteristics, Figure S1. HILIC-PDA-ESI/MS TIC chromatogram (sum and separate TICs) of a standard mix solution (at $2 \mu \mathrm{g} \mathrm{mL} \mathrm{m}^{-1}$ ) of the four glycosides monitored, Figure S2. Sum and individual total ion chromatograms (TIC) (including $\mathrm{m} / \mathrm{z}$ ions) of a standard mix solution (at $2 \mu \mathrm{g} \mathrm{mL} \mathrm{m}^{-1}$ ) of the four glycosides monitored, Figure S3. Rebaudioside A detection in the methanolic extract of Stevia leaves (SIM chromatogram).

Author Contributions: Conceptualization, N.N.; methodology, N.N., K.M.K., E.B., C.L.S.; software, N.N., K.M.K., E.B.; data curation, N.N., K.M.K., E.B.; writing-original draft preparation, N.N., K.M.K.; supervision, N.N., K.M.K., K.M. All authors have read and agreed to the published version of the manuscript.

Funding: This work was supported by the Research Infrastructure "Upgrading the Plant Capital (PlantUp)" (MIS 5002803) which is implemented under the Action "Reinforcement of the Research and Innovation Infrastructure", funded by the Operational Program "Competitiveness, Entrepreneurship and Innovation" (NSRF 2014-2020) and co-financed by Greece and the European Union (European Regional Development Fund). 
Acknowledgments: The authors are grateful to T. Koufakis and AGRIS SA for providing tomato seeds and seedlings as well as to the company Intrachem for the product NemGuard SC. We are also grateful to the Ever Stevia, Canada for the kind offer of Stevia rebaudiana, variety SugHigh A3.

Conflicts of Interest: The author declares no conflict of interest.

\section{Abbreviations}

LP

WP

LWE

WWE

$\mathrm{EO}$

GC/MS

UHPLC-HRMS

HPLC-PDA-ESI/MS
Culture residues in the form of leaves powder culture residues in the form of wood powder leaves water extract wood water extract essential oil Gas Chromatography/Mass Spectrometry Ultra High Performance Liquid Chromatography coupled to Orbitrap High Resolution Mass Spectrometry High-Performance Liquid Chromatography-Photo Diode Array Electrospray Mass Spectrometry

\section{References}

1. Kinghorn, A.D.; Soejarto, D.D. Current status of stevioside as a sweetening agent for human use. In Progress in Medicinal and Economic Plant Research; Wagner, H., Hikino, H., Farnsworth, N.R., Eds.; Academic Press: London, UK, 1985; Volume 1, pp. 1-52.

2. Soejarto, D.D.; Compadre, C.M.; Medon, P.J.; Kamath, S.K.; Kinghorn, A.D. Potential sweetening agents of plant origin. II. Field search for sweet-tasting Stevia species. Econ. Bot. 1983, 37, 71-79. [CrossRef]

3. Soejarto, D.D. Botany of stevia and Stevia rebaudiana. In Stevia: The Genus Stevia, Medicinal and Aromatic Plants-Industrial Profiles Series; Kinghorn, A.D., Ed.; Taylor \& Francis: London, UK, 2002; Volume 19, pp. 18-39.

4. Soejarto, D.D. Ethnobotany of stevia and Stevia rebaudiana. In Stevia: The Genus Stevia, Medicinal and Aromatic Plants-Industrial Profiles Series; Kinghorn, A.D., Ed.; Taylor \& Francis: London, UK, 2002; Volume 19, pp. 18-39.

5. Soejarto, D.D.; Addo, E.M.; Kinghorn, A.D. Highly sweet compounds of plant origin: From ethnobotanical observations to wide utilization. J. Ethnopharmacol. 2019, 243, 112056. [CrossRef] [PubMed]

6. Bertoni, M.S. Le Kaá-êhé-Sa nature et ses proprieties. An. Científicos Parag. Sér. I 1905, 5, 1-14.

7. Bertoni, M.S. La Stevia rebaudiana Bertoni. An. Científicos Parag. Sér. II 1918, 2, 129-134.

8. Singh, D.P.; Kumari, M.; Prakash, H.G.; Rao, G.P.; Solomon, S. Phytochemical and Pharmacological Importance of Stevia: A Calorie-Free Natural Sweetener. Sugar Tech. 2019, 21, 227-234. [CrossRef]

9. Kurek, J.M.; Krejpcio, Z. The functional and health-promoting properties of Stevia rebaudiana Bertoni and its glycosides with special focus on the antidiabetic potential-A review. J. Funct. Foods 2019, 61, 103465. [CrossRef]

10. Mejia, E.; Pearlman, M. Natural alternative sweeteners and diabetes management. Curr. Diabetes Rep. 2019, 19, 142. [CrossRef]

11. Salehi, B.; López, M.D.; Martínez-López, S.; Victoriano, M.; Sharifi-Rad, J.; Martorell, M.; Rodrigues, C.; Martins, N. Stevia rebaudiana Bertoni bioactive effects: From in vivo to clinical trials towards future therapeutic approaches. Phytoth. Res. 2019, 33, 2904-2917. [CrossRef]

12. Pawar, R.S.; Krynitsky, A.J.; Rader, J.L. Sweeteners from plants-With emphasis on Stevia rebaudiana (Bertoni) and Siraitia grosvernorii (Swingle). Anal. Bioanal. Chem. 2013, 405, 4397-4407. [CrossRef]

13. Turko, Y.A.; Korobko, N.V.; Shokun, V.V.; Chernyak, E.N.; Vyalkov, A.I.; Stepankina, O.N.; Kerimzhanova, B.F.; Baltaev, U.A. GC-MS research. I. Essential oil from Stevia rebaudiana. Chem. Nat. Compd. 2007, 43, 744-745. [CrossRef]

14. Hossain, M.A.; Siddique, A.B.; Rahman, S.M.M.; Hossain, M.A. Chemical composition of the essential oils of Stevia rebaudiana Bertoni leaves. Asian. J. Tradit. Med. 2015, 5, 56-61. 
15. Ramírez, P.G.; Ramírez, D.G.; Mejía, E.Z.; Ocampo, S.A.; Díaz, C.N.; Rojas Martínez, R.I. Extracts of Stevia rebaudiana against Fusarium oxysporum associated with tomato cultivation. Sci. Hortic. 2020, 259, 108683. [CrossRef]

16. Shukla, S.; Mehta, A.; Bajpai, V.K. Phytochemical screening and anthelmintic and antifungal activities of leaf extracts of Stevia rebaudiana. J. Biol. Act. Prod. Nat. 2013, 3, 56-63.

17. European Commission. Council directive 91/414/EEC of 15 July 1991 concerning the placing of plant protection products on the market. Off. J. Eur. Communities L 1991, 230, 1-32.

18. European Commission. Regulation (EC) No 1107/2009 of the European 515 Parliament and of the Council of 21 October 2009 concerning the placing of plant 516 protection products on the market and repealing Council Directives 79/117/EEC 517 and 91/414/EEC. Off. J. Eur. Union 2009, 309, 1-50.

19. Hernández-Carlos, B.; Gamboa-Angulo, M. Insecticidal and nematicidal contributions of Mexican flora in the search for safer biopesticides. Molecules 2019, 24, 897. [CrossRef]

20. Adenubi, O.T.; Ahmed, A.S.; Fasina, F.O.; McGaw, L.J.; Eloff, J.N.; Naidoo, V. Pesticidal plants as a possible alternative to synthetic acaricides in tick control: A systematic review and meta-analysis. Ind. Crops Prod. 2018, 123, 779-806. [CrossRef]

21. Ntalli, N.G.; Menkissoglu-Spiroudi, U. Pesticides of Botanical Origin: A Promising Tool in Plant Protection. Pesticides-Formulations, Effects, Fate; IntechOpen: London, UK, 2011; ISBN 978-953-7619-X-X.

22. Verdejo-Lucas, S.; Talavera, M. Root-knot nematodes on zucchini (Cucurbita pepo subsp. pepo): Pathogenicity and management. Crop Prot. 2019, 126, 104943. [CrossRef]

23. Jones, J.T.; Haegeman, A.; Danchin, E.G.; Gaur, H.S.; Helder, J.; Jones, M.G.; Kikuchi, T.; Manzanilla-López, R.; Palomares-Rius, J.E.; Wesemael, W.M.; et al. Top 10 plant-parasitic nematodes in molecular plant pathology. Mol. Plant Pathol. 2013, 14, 946-961. [CrossRef]

24. Ciulu, M.; Quirantes-Piné, R.; Spano, N.; Sanna, G.; Borrás-Linares, I.; Segura-Carretero, A. Evaluation of new extraction approaches to obtain phenolic compound-rich extracts from Stevia rebaudiana Bertoni leaves. Ind. Crops Prod. 2017, 108, 106-112. [CrossRef]

25. Karaköse, H.; Müller, A.; Kuhnert, N. Profiling and Quantification of Phenolics in Stevia rebaudiana Leaves. J. Agric. Food Chem. 2015, 63, 9188-9198. [CrossRef]

26. Directive 2008/98/EC of the European Parliament and of the Council of 19 November 2008 on Waste and Repealing Certain Directives; Document 32008L0098; European Parliament: Strasbourg, France, 2008.

27. SANCO/10363/2012-rev.9 Working Document on the Procedure for Application of Basic Substances to be Approved in Compliance with Article 23 of Regulation (EC) No 1107/2009; European Commission Health \& Consumers Directorate-General: Copenhagen, Denmark, 2009.

28. Briedel, M.; Lavielle, R. Sur le principe sucré des feuilles de Kaá-êh-é (Stevia rebaudiana B). Acad. Sci. Paris C. R. 1931, 192, 1123-1125.

29. Kohda, H.; Kasai, R.; Yamasaki, K.; Murakami, K.; Tanaka, O. New sweet diterpene glycosides from Stevia rebaudiana. Phytochemistry 1976, 15, 981-983. [CrossRef]

30. Kasai, R.; Kaneda, N.; Tanaka, O.; Yamasaki, K.; Sakamoto, I.; Morimoto, K.; Okada, S.; Kitahata, S.; Furakawa, H. Sweet diterpene-glycosides of leaves of Stevia rebaudiana Bertoni-Synthesis and structure-sweetness relationships of rebaudiosides- A, -D, -E and their related glycosides. Nippon Kagaku Kaishi 1981, 5, 726-735. [CrossRef]

31. Tanaka, O. Steviol-glycosides: New natural sweeteners. Trends Anal. Chem. 1982, 1, 246-248. [CrossRef]

32. Kennelly, E.J. Sweet and non-sweet constituents of Stevia rebaudiana. In Stevia: The Genus Stevia, Medicinal and Aromatic Plants_Industrial Profiles Series; Kinghorn, A.D., Ed.; Taylor \& Francis: London, UK, 2002; Volume 19, pp. 68-85.

33. Ntalli, N.G.; Ferrari, F.; Giannakou, I.; Menkissoglu-Spiroudi, U. Phytochemistry and nematicidal activity of the essential oils from 8 greek lamiaceae aromatic plants and 13 terpene components. J. Agric. Food Chem. 2010, 58, 7856-7863. [CrossRef] [PubMed]

34. Ntalli, N.G.; Ferrari, F.; Giannakou, I.; Menkissoglu-Spiroudi, U. Synergistic and antagonistic interactions of terpenes against Meloidogyne incognita and the nematicidal activity of essential oils from seven plants indigenous to Greece. Pest Man. Sci. 2011, 67, 341-351. [CrossRef]

35. Bai, P.H.; Bai, C.Q.; Liu, Q.Z.; Du, S.S.; Liu, Z.L. Nematicidal activity of the essential oil of Rhododendron anthopogonoides aerial parts and its constituent compounds against Meloidogyne incognita. Z. Naturforsch. C J. Biosci. 2013, 68C, 307-312. [CrossRef] 
36. Duschatzky, C.B.; Martinez, A.M.; Almeida, N.V.; Bonivardo, S.L. Nematicidal Activity of the Essential Oils of Several Argentina Plants Against the Root-Knot Nematode. J. Essent. Oil Res. 2004, 16, 626-628. [CrossRef]

37. Guo, L.; Wu, J.-Z.; Han, T.; Cao, T.; Rahman, K.; Qin, L.-P. Chemical Composition, Antifungal and Antitumor Properties of Ether Extracts of Scapania verrucosa Heeg. and its Endophytic Fungus Chaetomium fusiforme. Molecules 2008, 13, 2114-2125. [CrossRef]

38. da Silva, S.E.L.; Minguzzi, S.; da Silva, R.C.L.; Matos, M.F.C.; Tofoli, D.; de Carvalho, J.E.; Ruiz, A.L.T.G.; da Costa, W.F.; Simionatto, E. Chemical Composition and Cytotoxic Activity of the Root Essential Oil from Jatropha ribifolia (Pohl) Baill (Euphorbiaceae). J. Braz. Chem. Soc. 2015, 26, 233-238.

39. Arriola, N.D.A.; Chater, P.I.; Wilcox, M.; Lucini, L.; Rocchetti, G.; Dalmina, M.; Pearson, J.P.; Amboni, R.D.d.M.C. Encapsulation of stevia rebaudiana Bertoni aqueous crude extracts by ionic gelationEffects of alginate blends and gelling solutions on the polyphenolic profile. Food Chem. 2019, 275, 123-134. [CrossRef] [PubMed]

40. Chin, S.; Behm, C.A.; Mathesius, U. Functions of Flavonoids in Plant-Nematode Interactions. Plants 2018, 7, 85. [CrossRef] [PubMed]

41. Luo, C.; Wang, A.; Wang, X.; Li, J.; Liu, H.; Wang, M.; Wang, L.; Lai, D.; Zhou, L. A new proline-containing flavonol glycoside from Caragana leucophloea Pojark. Nat. Prod. Res. 2015, 29, 1811-1819. [CrossRef]

42. Rios, M.Y.; León-Rivera, I.; Ríos-Gomez, R.; Córdova-Albores, L.C.; Aguilar-Guadarrama, A.B. Phytotoxic and nematicide evaluation of Croton ehrenbergii (Euphorbiaceae). Pest Man. Sci. 2019, 75, 2165. [CrossRef]

43. Abdel Bar, F.M.; Ibrahim, D.S.; Gedara, S.R.; Abdel-Raziq, M.S.; Zaghloul, A.M. Nematicidal compounds from the leaves of Schinus terebinthifolius against root-knot nematode, Meloidogyne incognita infecting tomato. Nat. Prod. Sci. 2018, 24, 272-283. [CrossRef]

44. Caboni, P.; Saba, M.; Tocco, G.; Casu, L.; Murgia, A.; Maxia, A.; Menkissoglu-Spiroudi, U.; Ntalli, N. Nematicidal activity of mint aqueous extracts against the root-knot nematode Meloidogyne incognita. J. Agric. Food Chem. 2013, 61, 9784-9788. [CrossRef]

45. Zinoveva, S.V.; Vasyukova, N.I.; Il'inskaya, L.I.; Udalova, Z.V.; Ozeretskovskaya, O.L. Immunization of tomato plants against root-knot nematode Meloidogyne incognita with biogenic elicitors. Appl. Bioch. Microb. 1997, 33, 293-296.

46. Hajji-Hedfi, L.; Larayedh, A.; Hammas, N.-C.; Regaieg, H.; Horrigue-Raouani, N. Biological activities and chemical composition of Pistacia lentiscus in controlling Fusarium wilt and root-knot nematode disease complex on tomato. Eur. J. Plant Path. 2019, 155, 281-291. [CrossRef]

47. Machado, A.R.T.; Ferreira, S.R.; da Silva Medeiros, F.; Fujiwara, R.T.; de Souza Filho, J.D.; Pimenta, L.P.S. Nematicidal activity of Annona crassiflora leaf extract on Caenorhabditis elegans. Parasites Vectors 2015, 8, 113. [CrossRef]

48. Hussey, R.S.; Barker, K.R. Comparison of methods of collecting inocula of Meloidogyne spp. including a new technique. Plant Dis. Rep. 1973, 57, 1025-1028.

49. Pantelelis, I.; Karpouzas, D.G.; Menkissoglu-Spiroudi, U.; Tsiropoulos, N. Influence of soil physicochemical and biological properties on the degradation and adsorption of the nematicide fosthiazate. J. Agric. Food Chem. 2006, 54, 6783-6789. [CrossRef]

50. Ntalli, N.; Parlapani, A.B.; Tzani, K.; Samara, M.; Boutsis, G.; Dimou, M.; Menkissoglu-Spiroudi, U.; Monokrousos, N. Thymus citriodorus (Schreb) botanical products as ecofriendly nematicides with bio-fertilizing properties. Plants 2020, 9, 202. [CrossRef] [PubMed]

51. Weber, J.B.; Wilkerson, G.G.; Linker, H.M.; Wilcut, J.W.; Leidy, R.B.; Senseman, S.; Witt, W.W.; Barrett, M.; Vencill, W.K.; Shaw, D.R.; et al. A proposal to standardize soil/solution herbicide distribution coefficients. Weed Sci. 2000, 48, 75-88. [CrossRef]

52. Byrd, D.W.; Krikpatrick, T.; Barker, K.R. An improved technique for cleaning and staining plant tissue for detection of nematodes. J. Nematol. 1983, 15, 142-143.

53. Pacifico, S.; Piccolella, S.; Nocera, P.; Tranquillo, E.; Dal Poggetto, F.; Catauro, M. Steviol glycosides content in cultivated Stevia rebaudiana Bertoni: A new sweet expectation from the Campania region (Italy). J. Food Compos. Anal. 2017, 63, 111-120. [CrossRef]

54. ICH. Validation of Analytical Procedures: Text and Methodology Q2 (R1). Available online: http://wwwichorg/ fileadmin/Public_Web_Site/ICH_Products/Guidelines/Quality/Q2_R1/Step4/Q2_R1_Guidelinepdf (accessed on 5 November 2018). 
55. SANTE/11813/2017. Guidance Document on Analytical Quality Control and Validation Procedures for Pesticide Residues Analysis in Food and Feed. Available online: https:/ec.europa.eu/food/sites/food/files/ plant/docs/pesticides_mrl_guidelines_wrkdoc_2017-11813.pdf (accessed on 10 December 2018).

56. Betz, J.M.; Brown, P.N.; Roman, M.C. Accuracy, precision, and reliability of chemical measurements in natural products research. Fitoterapia 2011, 82, 44-52. [CrossRef]

57. Puntener, W. Manual for field trials. In Plant Protection, 2nd ed.; Ciba Geigy Limited: Basle, Switzerland, 1981; p. 205.

58. Seefeldt, S.S.; Jensen, J.E.; Fuerst, E.P. Log-logistic analysis of herbicide dose-response relationships. Weed Technol. 1995, 9, 218-227. [CrossRef]

(C) 2020 by the authors. Licensee MDPI, Basel, Switzerland. This article is an open access article distributed under the terms and conditions of the Creative Commons Attribution (CC BY) license (http://creativecommons.org/licenses/by/4.0/). 